\title{
ERS/ATS workshop report on respiratory health effects of household air pollution
}

\author{
Akshay Sood ${ }^{1}$, Nour A. Assad ${ }^{1}$, Peter J. Barnes ${ }^{2}$, Andrew Churg ${ }^{3}$, \\ Stephen B. Gordon ${ }^{4}$, Kevin S. Harrod (10 ${ }^{5}$, Hammad Irshad ${ }^{6}$, Om P. Kurmi $\mathbb{1}^{7}$, \\ William J. Martin $I^{8}$, Paula Meek ${ }^{9}$, Kevin Mortimer ${ }^{4}$, Curtis W. Noonan ${ }^{10}$, \\ Rogelio Perez-Padilla ${ }^{11}$, Kirk R. Smith ${ }^{12}$, Yohannes Tesfaigzi ${ }^{6}$, Tony Ward ${ }^{10}$ and \\ John Balmes ${ }^{12,13}$
}

Affiliations: ${ }^{1}$ University of New Mexico School of Medicine, Albuquerque, NM, USA. ${ }^{2}$ National Heart and Lung Institute, Imperial College London, London, UK. ${ }^{3}$ University of British Columbia, Vancouver, BC, Canada. ${ }^{4}$ Liverpool School of Tropical Medicine, Liverpool, UK. ${ }^{5}$ University of Alabama at Birmingham, Birmingham, AL, USA. ${ }^{6}$ Lovelace Respiratory Research Institute, Albuquerque, NM, USA. ${ }^{7}$ University of Oxford, Oxford, UK. ${ }^{8}$ Ohio State University, Columbus, OH, USA. ${ }^{9}$ University of Colorado at Denver, Denver, CO, USA. ${ }^{10}$ University of Montana, Missoula, MT, USA. ${ }^{11}$ Instituto Nacional de Enfermedades Respiratorias, Mexico City, Mexico. ${ }^{12}$ University of California School of Public Health, Berkeley, CA, USA. ${ }^{13}$ University of California, San Francisco, CA, USA.

Correspondence: Akshay Sood, Division of Pulmonary, Critical Care and Sleep Medicine, Dept of Internal Medicine, University of New Mexico School of Medicine, 1 University of New Mexico, MSC 105550, Albuquerque, NM 87131, USA. E-mail: asooddasalud.unm.edu

@ERSpublications

Respiratory diseases from household air pollution are preventable for 2.8 billion people worldwide http://ow.ly/H1bG30fuwp4

Cite this article as: Sood A, Assad NA, Barnes PJ, et al. ERS/ATS workshop report on respiratory health effects of household air pollution. Eur Respir J 2018; 51: 1700698 [https://doi.org/10.1183/13993003.006982017].

ABSTRACT Exposure to household air pollution (HAP) from solid fuel combustion affects almost half of the world population. Adverse respiratory outcomes such as respiratory infections, impaired lung growth and chronic obstructive pulmonary disease have been linked to HAP exposure. Solid fuel smoke is a heterogeneous mixture of various gases and particulates. Cell culture and animal studies with controlled exposure conditions and genetic homogeneity provide important insights into HAP mechanisms. Impaired bacterial phagocytosis in exposed human alveolar macrophages possibly mediates several HAP-related health effects. Lung pathological findings in HAP-exposed individuals demonstrate greater small airways fibrosis and less emphysema compared with cigarette smokers. Field studies using questionnaires, air pollution monitoring and/or biomarkers are needed to better establish human risks. Some, but not all, studies suggest that improving cookstove efficiency or venting emissions may be associated with reduced respiratory symptoms, lung function decline in women and severe pneumonia in children. Current studies focus on fuel switching, stove technology replacements or upgrades and air filter devices. Several governments have initiated major programmes to accelerate the upgrade from solid fuels to clean fuels, particularly liquid petroleum gas, which provides research opportunities for the respiratory health community.

This document was endorsed by the ERS Science Council and Executive Committee in September 2017, and approved by the ATS Board of Directors in October 2017.

Received: April 032017 | Accepted after revision: Aug 082017

Support statement: The Task Force workshop was supported by the National Institute of Environmental Health Sciences (R12ES 024652-01), American Thoracic Society, European Respiratory Society and Global Alliance for Clean Cookstoves. Funding information for this article has been deposited with the Crossref Funder Registry.

Conflict of interest: None declared.

Copyright @ERS 2018 


\section{Introduction}

More than 2.8 billion people worldwide use solid fuel for cooking, with many more using solid fuels for heating homes [1]. Combustion of solid fuels in inefficient stoves in poorly ventilated homes leads to household air pollution (HAP). The greatest proportions of the populations exposed to HAP are in countries of sub-Saharan Africa, India, China and Central America [1]. Although the exposure burden is highest in low-income countries, a significant number of households in high-income countries rely on solid fuel for heating homes.

Solid fuels include wood, charcoal, crop residues and animal dung (collectively referred to as biomass fuels), and coal [2]. With inefficient combustion of these solid fuels, a complex mixture of carbon-based particles, inorganic particles and irritant gases is generated, which shares some characteristics with that of tobacco smoke and includes carcinogens. Observational studies demonstrate strong associations between exposure to HAP and childhood respiratory tract infections, chronic obstructive pulmonary disease (COPD), lung cancer, cataracts and low birthweight of children, with limited evidence supporting associations with cardiovascular disease [3-6]. Although the reports in the literature are conflicting, the risk for asthma and tuberculosis may also be increased among those exposed [7-10].

The Comparative Risk Assessment for the 2010 Global Burden of Disease lists HAP as the third highest risk factor for disability-adjusted life years [5]. This was based on a detailed assessment of the health impacts by the HAP Expert Group [11]. Owing to this high burden of disease, further research is needed to address important data gaps, including how clean cookstoves need to be in order to substantially reduce health risks, the limited epidemiological evidence for cardiovascular disease risk, mechanistic understanding of the toxicity of exposure to HAP and barriers towards adopting clean cooking alternatives. The Global Alliance for Clean Cookstoves initiative hosted by the United Nations Foundation to enable the distribution of 100 million clean stoves by 2020 and the initiatives of a number of governments to accelerate the progression away from biomass to clean fuels provide a major impetus to conduct research needed to address these data gaps.

\section{Methods}

A scientific workshop on HAP was held by a specially constituted Task Force at Denver, CO, USA, in May 2015, in conjunction with the American Thoracic Society (ATS) International Conference. The Task Force chairs (A. Sood and J. Balmes) were the principal investigators of the National Institute of Environmental Health Sciences grant R12ES 024652-01 that primarily funded the workshop. The chairs were also approved by the European Respiratory Society (ERS) and ATS, which provided partial funding. In addition, the Global Alliance for Clean Cookstoves provided partial funding for the workshop. None of the sponsors played any role in the selection of Task Force panellists or topics, or the creation of the workshop report.

The chairs led all aspects of project management and invited 17 other panellists to the workshop, based on the following criteria: 1) basic, clinical or epidemiological experience in research on this field, and 2) diversity with respect to sex, race and geography. Additional workshop attendees based on the above criteria were invited to ensure that broad expertise in this field from five continents was represented. All panellists were required to disclose their conflicts of interest. The disclosures of conflicts of interest were reviewed by the ATS and ERS, and none were found.

The topics for the scientific workshop were chosen based upon the input from the chairs and the panellists, and included recent advances in basic, clinical, epidemiological and policy aspects related to HAP. All panellists were requested to perform a literature review using MEDLINE, using key words related to their specific topic prior to the workshop and limiting their search to articles in English. The MEDLINE search was initially completed by May 2015 prior to the workshop and was subsequently updated by February 2017. The findings of the panellists were presented and discussed at the workshop. The panellists were subsequently invited to submit short sections on their topic, summarising the current state of the literature, existing critical gaps and the discussion by attendees at the workshop. This report summarises the proceedings of the workshop, with limited update on new literature published in the interim period. After undergoing three rounds of review, the workshop report was approved by all panellists participating in the creation of the manuscript. The structure of the report follows the general outline of the workshop.

\section{Content of solid fuel smoke}

Studies of exposure to HAP are enhanced by a basic understanding of the physical and chemical characteristics of solid fuel smoke. Wood, the most commonly used solid fuel, is composed of approximately $70 \%$ cellulose and 30\% lignin. The combustion byproducts of wood include various gases (nitrogen oxides, carbon monoxide (CO) and carbon dioxide), particulate matter including those with 
median aerodynamic diameter $\leqslant 2.5 \mu \mathrm{m}(\mathrm{PM} 2.5)$ that consists of hydrocarbons and inorganic particles, and semivolatile organic compounds [12]. The combustion emissions of wood vary in amount, composition and particle size, depending on combustion characteristics (e.g. air supply, amount of wood burned, size of fuel bed, time in burn cycle and atmospheric pressure), wood characteristics (e.g. type of wood, wood moisture and shape/size of wood) and appliance characteristics (e.g. type of appliance, appliance operation and draft of air).

Laboratory studies of combustion emissions of wood, although expensive, have the opportunity to characterise the exposure in detail. Given the variability of wood smoke, laboratory studies require attention to the characteristics of combustion, wood and appliance, and to the study design, to capture the parameters of interest. The measurement of particulate matter involves real-time and non-real-time filter collection techniques that give information about gravimetric data and chemical composition as well as recording the relative variations of the magnitude of particulate exposure. The challenge in the measurement of smoke exposure for all solid fuel combustion studies lies in defining the variables and measurements of importance, while keeping it economically and logistically feasible.

\section{Difference between solid fuel and tobacco smoke}

Although the size of particulate matter in both tobacco smoke and HAP is small enough to reach distal airways [13], there are important differences between the two exposures. Despite the progressive decrease in the percentage of people using solid fuels, the absolute population exposed to HAP is more than three times greater than those smoking daily (i.e. more than 2800 million versus 980 million) [6, 14]. Especially concerning is the fact that as more women start to smoke in rural areas of low-income countries, they could experience combined smoking and HAP exposures. In terms of estimated inhaled (nominal) dose of PM2.5, cooking in kitchens with substantial HAP (i.e. $\geqslant 666 \mu \mathrm{g} \cdot \mathrm{m}^{-3}$ ) may be equivalent to smoking 1 cigarette per day (assuming an average minute ventilation rate of $18 \mathrm{~m}^{3} \cdot \mathrm{day}^{-1}$ ) and therefore a heavy smoker has an inhaled particulate matter dose many times higher than typical exposures estimated in people exposed to HAP while cooking [15-18]. These rather coarse estimates allow a comparison of risks for diseases across different types of injurious exposures (e.g. HAP versus active smoking). In addition, equivalence would only be in terms of inhaled dose, but unfortunately there is no reliable information about the dose of pollutants that reach the bloodstream or the target organs.

Recently, a number of key gaps in our knowledge about lung disease and HAP exposure were identified [19]. For example, it is not known if the different mixtures of pollutants contribute differentially to the health risks or if additive effects are present with HAP and smoking exposures. We also lack information about internal dose, clearance of pollutants and the relevance of the timecourse of HAP, as the most important pollutants are likely those remaining for long periods in the body and acting during key periods of lung development or repair. In this regard, exposure to HAP is over a long-term timeframe, including critical periods of lung development [20], starting before birth, continuing during infancy and adulthood, and with circadian oscillations, including moments with very high peak levels of pollutants during cooking. This pattern is very different to that of tobacco smoking and could explain the relatively higher risk of COPD found in epidemiological studies of HAP exposures compared with what might be expected from mean exposure values [15-18]. A better understanding of the differences between diseases associated with tobacco smoke and HAP could be obtained if we are able to develop specific biomarkers related to acute and chronic (cumulative) HAP exposure or intermediate phenotypes of lung damage [21].

\section{Exposure assessment using questionnaires}

Historically, HAP exposures have been assessed through face-to-face surveys. The World Health Organization (WHO) has used an extensive survey, administered face-to-face, to report on smoke exposure, burning conditions and symptoms during cooking and household work in low-income countries [22]. These types of surveys are lengthy, costly, and require significant time commitment and significant training of the observer to maintain reproducibility of the scoring or reports. However, survey-based answers, although imprecise, can be as stable as short-term (i.e. 24-72 h) measurements of pollutants in household settings $[23,24]$. Thus, self-reported exposure histories can be as useful for epidemiology, as has been shown in many dozen studies. Additionally, some work has been done to develop a simple HAP index of exposure in low-income countries, calculated using the daily average number of hours spent cooking multiplied by the total number of years spent cooking personally, and was used to evaluate the risk of chronic bronchitis in rural women living in India, with limited validation data provided by the authors [25]. External validation of this index in additional cohorts in low-income countries is required.

HAP in high-income countries differs in magnitude, type and pattern from low-income countries. Healthcare providers and public health officials in high-income countries often rely on the use of single questions (e.g. "About how many hours are you exposed to indoor smoke or do you burn wood?"). There 
is a need for a self-report questionnaire that could provide a clear means of assessing the type and magnitude of HAP exposure in high-income countries. Self-report questionnaires provide a standardised way of recording an individual's perception of exposure, thus providing consistency across respondents and allowing for classic psychometric testing that help support reproducibility and validity of the scores obtained. This approach may be of clear value if assessment of HAP exposure is to be incorporated in ongoing health assessments in high-income countries. Currently, work is underway to study a self-report questionnaire modified from the WHO survey questions, to measure household wood smoke exposure that could be used in high-income countries. This Magnitude of Household Wood Smoke Index is a self-report measure that has undergone content validity, and is being piloted to determine its reproducibility and validity [23].

\section{Markers of exposure}

As studies of health effects of HAP shift from associational studies to testing of interventions, the need for simple and reliable assessment of exposure to HAP has become more pressing.

Most HAP studies rely on fixed or personal particulate matter air monitors (or surrogate CO monitors), but such approaches can be expensive, technically and logistically challenging, and difficult to employ for repeated measures in large populations [21]. To date, efforts to identify reliable markers for HAP exposures have focused primarily on three areas: CO, urinary metabolites of specific wood smoke markers and urinary polycyclic aromatic hydrocarbon (PAH) metabolites. Air monitoring of $\mathrm{CO}$, a byproduct of incomplete combustion, has been used as a proxy for HAP in high-exposure settings [26], although a recent meta-analysis indicates wide variance in agreement between personal CO and PM2.5 measures [27]. Exhaled $\mathrm{CO}$ or blood carboxyhaemoglobin $(\mathrm{COHb})$ have been used to demonstrate intervention changes in high-exposure cookstove settings [28-30], but application of exhaled $\mathrm{CO}$ or $\mathrm{COHb}$ measures in large-scale, repeated measures studies can be challenging. The use of transcutaneous measures of $\mathrm{COHb}$ saturation is an intriguing alternative strategy, but requires further development to ensure sufficient sensitivity and reliability [31].

Among the candidate urinary biomarkers, guiacols have shown some promise as a representative set of chemical constituents related to wood combustion [32-34]. Levoglucosan, a sugar anhydride released by combustion of cellulose, was demonstrated as a reasonable wood smoke biomarker in animal exposure models, but human studies were not promising, likely due to dietary sources of levoglucosan [35, 36]. Finally, urinary $\mathrm{PAH}$ metabolites have been shown to reflect response to interventions in high-exposure cookstove settings $[37,38]$. As with other candidate urinary biomarkers for HAP exposure, analysis of urinary PAH metabolites is costly and technically challenging. While there are several potential HAP biomarkers, further discovery is required to identify a simple, reliable and inexpensive biomarker that is useful across a wide range of exposure settings.

\section{Animal studies}

The complex nature of wood smoke and its effects on various pathways explain the uncertainty in the underlying cellular and molecular mechanisms for respiratory diseases related to HAP. Therefore, cell culture and animal studies with controlled exposure conditions and homogeneity of genetic variation can provide important reproducible insights into HAP mechanisms, identify susceptibility traits and allow the design of effective intervention strategies.

Cell culture studies have shown that wood smoke activates calcium channel transient receptor potential ankyrin-1 via electrophile/oxidant recognition sites [39], and that wood smoke can increase reactive oxygen species by sequestering iron and can cause DNA damage to activate the p53 pathway [40-43]. Furthermore, monocytes can be triggered by wood smoke to produce inflammatory cytokines, including interleukin (IL)-8, tumour necrosis factor- $\alpha$ and monocyte chemotactic protein-1 [44]. The reactive oxygen species generated by wood smoke can cause proliferation of alveolar type II epithelial cells [45], but conversely cell death in endothelial cells [46], thus underlining the complexity of mechanistic studies conducted in animals.

Exposure of guinea pigs to wood smoke over $4-7 \mathrm{months}$ at $500 \mu \mathrm{g} \cdot \mathrm{m}^{-3}$ total particulate matter concentration causes airway inflammation and emphysema [47], and exposure of allergic Brown Norway rats or $\mathrm{BALB} / \mathrm{c}$ mice at $300-1000 \mu \mathrm{g} \cdot \mathrm{m}^{-3}$ results in a mild increase in airway inflammation [48]. Recent studies reveal the mechanisms by which wood smoke enhances cigarette smoke-induced inflammation (figure 1). Upon prolonged exposure, cigarette smoke activates the nuclear arylhydrocarbon receptor (AHR) to initiate an anti-inflammatory pathway by inducing cyclooxygenase (COX)-2 and microsomal prostaglandin E synthase-1, and the production of lipoxins. Wood smoke at levels that do not induce inflammation blocks the cigarette smoke anti-inflammatory COX-2 pathway by inducing expression of AHR repressor to enhance cigarette smoke-induced airway inflammation in a synergistic fashion [49]. 


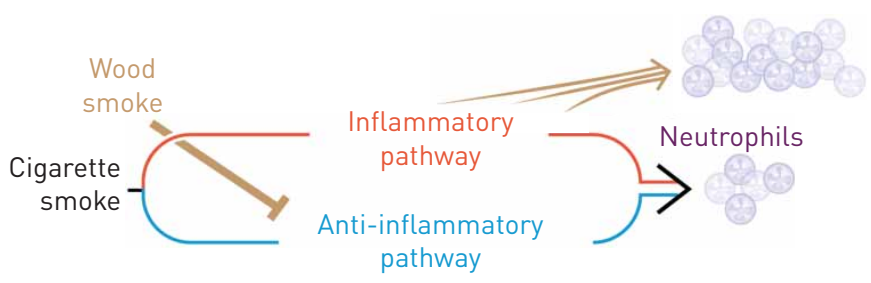

FIGURE 1 Schematic of mechanisms underlying the enhancement of cigarette smoke-induced neutrophilic inflammation by wood smoke. In addition to activating the inflammatory pathway, prolonged exposure to cigarette smoke activates an anti-inflammatory pathway. Wood smoke at levels that do not induce inflammation blocks the cigarette smoke-induced anti-inflammatory pathway and thereby enhances cigarette smoke-induced airway inflammation in a synergistic fashion. See Awı et al. [49] for details.

Overall, wood smoke at much lower concentrations than cigarette smoke can affect airway epithelial cells to respond by activating the p53 pathway $[42,43]$. Identification of compounds within wood smoke that cause this accentuated response will be important to better understand the signalling pathway and to develop targeted intervention strategies for wood smoke-induced chronic lung diseases.

\section{Role of human alveolar macrophages}

Alveolar macrophages phagocytose inhaled particles in the human lung [50]. Studies of human alveolar macrophages from exposed subjects in both low- and high-income countries demonstrate quantifiable loads of particulate matter in their cytoplasm [51, 52], which may help explain some of the adverse respiratory effects of chronic HAP exposure.

Human alveolar macrophages exposed to particulates ex vivo produce pro-inflammatory cytokines [53]. These observations, repeated in animal and human experiments, are consistent with the pneumonitis reported following acute "massive" smoke exposure, such as that experienced by firefighters and victims of house fires [54]. In contrast, carbon loading of alveolar macrophages in individuals with chronic "regular" smoke exposure, such as that experienced by people who cook with solid fuel, is associated with minimal pulmonary inflammation but with multiple lung health effects, including increased susceptibility to infection, carcinogenesis, impaired lung growth in children [55], impaired lung function in adults [51] and pathogenesis of chronic lung disease. The role of wood smoke on other types of inflammatory cells, including T-cells and dendritic cells, has not been adequately reported.

The increased susceptibility to infection in subjects exposed to HAP is explained by recent ex vivo studies that show carbon loading of human alveolar macrophages results in impaired bacterial phagocytosis and decreased bacterial killing [56]. The degree of impairment is more severe with wood smoke exposure than with fine carbon black and while proteolysis is preserved, oxidative responses are impaired in proportion to smoke exposure [57]. The impairment of oxidative response of the alveolar macrophage allows an explanation of the apparent paradox of the often asymptomatic chronic human exposure to HAP. Oxidative responses are integral to the pro-inflammatory cytokine cascade and so it may be hypothesised that this necessary counter-regulation against a potentially toxic threat results in impaired inflammatory responses to bacterial infection, and hence increased pneumonia. To date, however, although it has been demonstrated that while different baseline levels of cytokine production in alveolar macrophages are related to chronic regular smoke exposure, the acute responses to further smoke exposure have not been different. Future work will need to focus on specific cells, particularly the alveolar macrophage, as well as the specific smoke of interest, in order to give relevant answers to the question of how health-related effects of HAP are mediated.

\section{Respiratory tract infections}

Respiratory tract infections constitute the greatest cause of illness in children globally [58]. Although the underlying cause is not entirely known, exposure to HAP is strongly linked to respiratory infections, particularly among children, and to infectious exacerbations of chronic lung disease [59]. One possible mechanism involves HAP-related change in nasal carriage rates of Streptococcus pneumoniae, the most common cause of bacterial pneumonia. Pneumococcal carriage is common among asymptomatic individuals and is a predictor of pulmonary infection by $S$. pneumoniae [60]. In experimental human exposures to wood smoke, the duration and density of pneumococcal carriage is increased [56]. In addition to $S$. pneumoniae, sequencing of the oropharyngeal microbiome reveals subtle but substantive changes in the upper respiratory microbiome following wood smoke exposure [61].

It is plausible that HAP exposure may alter the respiratory mucosal microenvironment sufficiently to render individuals susceptible to common circulating pathogens either by dampening host mechanisms of 
protection against commensals or by facilitating microbial fitness in the respiratory tract. Furthermore, the contribution of HAP to chronic lung diseases such as COPD or chronic bronchitis may, in part, be manifest by recurrent respiratory infections due to enhanced susceptibility. More investigative endeavours are needed to fully understand the role of respiratory infections in the health effects to HAP exposure.

\section{Impaired lung growth in children}

Cross-sectional and longitudinal studies suggest that long-term exposure to pollutants (mainly from ambient air pollution) may adversely affect lung growth in children and young adults [62-66]. Nonasthmatic children with no history of smoking but exposure to low ambient air quality were found to have low levels of forced expiratory volume in $1 \mathrm{~s}\left(\mathrm{FEV}_{1}\right)$, broadly similar to those who reported exposure to maternal smoking and slightly worse than those who reported personal smoking [66]. GAUDERMAN et al. [66] also reported that a long-term improvement in ambient air quality improved lung function in children, but no such studies have investigated the effect on children regarding HAP.

The impact of exposure to HAP on lung growth during the early part of life has not been adequately addressed $[62,67,68]$. There is mounting evidence, mostly from high-income countries but some from low-income countries, that early life micronutrient intake plays a vital role in lung development and hence growth of lung function [69]. The combined effect of nutrient intake and HAP on lung growth has not been studied. It is also still not clear whether exposure to a "good" diet offsets the effect of "bad" HAP exposures. While other factors will also play a part, most notably nutritional status and maternal smoking, a specific study of lung development in relation to different types of solid fuel and relating these outcomes to the specific toxicity of the smoke has not been undertaken. What remains to be determined is whether exposure to HAP in early life is associated with low lung function and greater respiratory symptoms in childhood and ultimately in adulthood.

\section{Chronic obstructive pulmonary disease}

While cigarette smoking is the most common risk factor for COPD in high-income countries, recent studies from Spain [70], the USA [71] and Canada [72] report increased risk of COPD in HAP-exposed subjects. In low-income countries, cigarette smoking accounts for only half the cases [73] and HAP is a key risk factor for COPD, particularly in women $[59,74]$. As the vast majority of research in COPD has been conducted in smoking-related COPD, relatively little is known about the clinical course, lung function, inflammatory mechanisms or response to therapy in HAP-related COPD or how it differs from smoking-related COPD.

P.J. Barnes et al. (National Heart and Lung Institute, Imperial College London, London, UK; unpublished data) are currently undertaking detailed phenotyping on HAP-related COPD (mainly women) in villages in India, and comparing its phenotype to smoking-related COPD (mainly men) in the same community and to exposed nonobstructed individuals. For matched severity based on FEV1 \% predicted, there is little difference in symptoms, although mucus hypersecretion is more frequent in HAP-related COPD, consistent with other published literature [75-80]. The mechanisms that underlie greater mucus hypersecretion by wood smoke compared with cigarette smoke are under investigation. Respiratory quality of life scores may be similar but, in general, patients with HAP-related COPD have more chronic bronchitis symptoms and greater bronchial hyperresponsiveness, whereas smokers with COPD have more airflow obstruction and lower diffusing capacity, also consistent with other published literature [75-80]. Lung function measurements show that small airway disease, as measured by impulse oscillometry, may be more common in HAP-related COPD and this is supported by computed tomography scans showing greater small airway disease (as measured by low attenuation on expiration) and less emphysema than smoking-related COPD (J.P. Barnes et al.; unpublished data). The rate of decline in lung function [76] and the physiological severity of COPD [81] (as defined by the Global Initiative for Chronic Obstructive Lung Disease stage or BODE index) appears to be lower in HAP-related COPD compared with cigarette smoking-related COPD. Despite that, the survival in both types of COPD is similar [75]. Rural Indian women exposed to HAP may have increased systemic inflammation and a high prevalence of hypertension, compared with women using liquid petroleum gas (LPG) for cooking [82]. Lung cancer, which is 10 -fold more common in smoking-related COPD than normal smokers, is also reported in HAP-related COPD [83].

In induced sputum from patients with HAP-related COPD, J.P. Barnes et al. (unpublished data) note increased neutrophils and macrophages comparable to smoking-related COPD, with increased concentrations of CXCL8, IL-6 and 8-isoprotane; the latter is a biomarker of oxidative stress. In vitro exposure of macrophages to particulate matter collected from the rural homes by air extraction may release CXCL8 and IL-6 (J.P. Barnes et al.; unpublished data). This inflammatory effect is unlikely to be mediated by endotoxin as polymyxin does not significantly reduce this response and is likely to be mediated 
through oxidative stress. As with smoking-related COPD, there is a defect in bacterial phagocytosis by macrophages in HAP-related COPD which may predispose to bacterial colonisation of the lower airways [84] and this may be a susceptibility factor that predisposes to the development of airway obstruction after exposure to inhaled particulates.

There is a need to understand more about the natural history of HAP-related COPD, its associated comorbidities and its response to treatments, as no therapeutic trials have been conducted. As noted earlier, there is also a need to understand how HAP affects lung growth because smaller lungs may interact with accelerated decline in lung function and lead to earlier onset of COPD [85]. The importance of inadequate lung growth is underscored by the finding of a near-normal decline in lung function in women with HAP-related COPD in one study [74]. There is also a need to understand the genetic and epigenetic susceptibility to HAP, given that one study demonstrated that wood smoke exposure interacted in a multiplicative manner with aberrant promoter methylation of the p16 or GATA4 genes in sputum on lower FEV1 \% predicted [71].

\section{Lung pathological findings in HAP}

There is a remarkable paucity of information about the pathological findings in the lungs of individuals exposed to HAP. Many reports in the literature are simply uninterpretable in terms of modern notions of lung pathology [86]. Older reports that described "emphysema" utilised uninflated lung, so that the presence, type and severity of emphysema cannot be determined. Similarly, most old reports simply list "fibrosis" without detailing the configuration of the fibrosis. Many recent reports are based on transbronchial biopsies in which the nature and distribution of fibrosis cannot be easily determined. Within these limitations, the most consistent finding in lungs exposed to HAP appears to be lesions similar to pneumoconiosis-type dust macules (i.e. collections of particle-laden macrophages principally along the bronchovascular bundles), with deposition of black pigment and (by polarisation microscopy) birefringent particles with the characteristics of silicates or silica, in and around the walls of respiratory and, probably, membranous bronchioles (figure 2). Electron microscopic analysis has confirmed the presence of carbonaceous particles, silicates and silica [87], and wood smoke particles [88]. However, these lesions are not simple dust macules because the walls of the affected bronchioles are fibrotic. This idea has been confirmed in a Mexican study by Rivera et al. [86], who concluded that HAP exposure produced more bronchiolar fibrosis than did cigarette smoke. In many cases, the pneumoconiosis is limited to small airways. A similar type of airway-limited disease was described many years ago by CHURG et al. [89] in workers with various types of dust exposure and subsequently labelled "mineral dust airways disease", a process that appears to cause airflow obstruction. This small airways disease is probably the most important anatomical basis for airflow obstruction in HAP-exposed individuals.

In some cases of exposure to HAP, fibrosis spreads from the affected bronchioles through the interstitium to produce interstitial fibrosis that may be linear or may form mixed dust nodules (figure 2). Again, polarisation microscopy demonstrates that this more diffuse fibrosis contains silicate and silica particles, and black pigment is visible as well. All of these changes are consistent with a pneumoconiosis produced by a combination of silicates, silica and carbonaceous particles.

The only report that has quantified emphysema in this setting is that of RIVERA et al. [86], who concluded that both cigarette smoke- and HAP-exposed individuals develop emphysema, but that, relatively, the
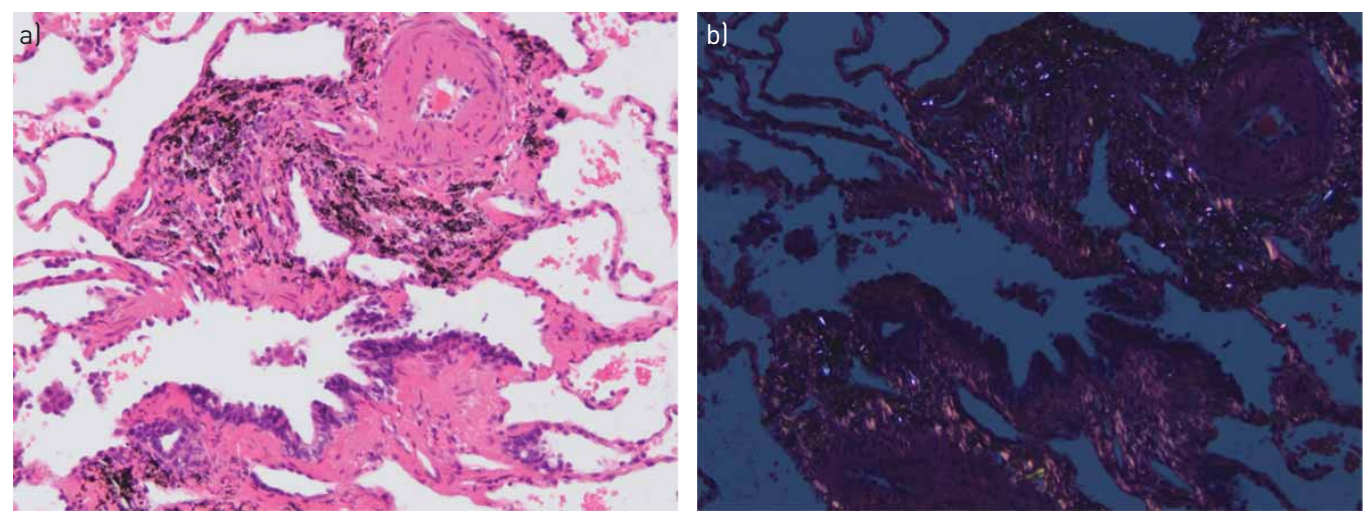

FIGURE 2 Lung biopsy from a woman known to have cooked with biomass fuel. a) High-power view shows marked fibrosis of the bronchioles with accompanying black pigment. Very focal early interstitial fibrosis spreading away from the bronchioles is also present. b) Polarisation microscopy demonstrates numerous birefringent particles in the fibrotic airway wall. 
emphysema is more severe in cigarette smokers; conversely, small airway fibrosis is more severe in HAP-exposed individuals. Rivera et al. [86] also described arterial intimal fibrosis in HAP-exposed patients; the functional consequences of this anatomical change are, however, unclear.

At this point, more data are needed on the basic pathology resulting from HAP. There is essentially no information on whether the pathological changes seen in the lung vary with the type of solid fuel being burned, and what the consequences of exposure to different types of solid fuel might be in regard to airway reversibility, if any, and pulmonary function.

\section{Useful interventions in low-income countries}

Two well-conducted randomised controlled trials (RCTs) have been published evaluating the effects of HAP exposure reduction interventions on health outcomes in low-income countries in North America [90, 91]. Both trials studied cookstoves that reduce exposure by venting emissions to the outdoor environment with a chimney rather than by improving combustion efficiency. The first trial compared a Patsari stove intervention (figure 3) with traditional open fire on respiratory symptoms and lung function in 552 women in Mexico [90]. Even though the adherence to the intervention was poor (50\%) and the intention-to-treat results were not significant, the use of the Patsari stove was associated with reduced respiratory symptoms and lung function decline ( 31 versus $62 \mathrm{~mL}$ over 1 year; $\mathrm{p}=0.01$ ). The Randomised Exposure Study of Pollution Indoors and Respiratory Effects (RESPIRE) trial randomised 534 households with a pregnant woman or infant in highland Guatemala to a Plancha stove (figure 4) or open fire and assessed the impact on pneumonia in children $<18$ months of age [91]. The Plancha stove was associated with a nonsignificant reduction in incidence of physician-diagnosed pneumonia (primary outcome) but a significant reduction in physician-diagnosed severe pneumonia (rate ratio 0.67, 95\% CI 0.45-0.98; $\mathrm{p}=0.04$ ) despite only a 50\% reduction in personal smoke and CO exposures and an improvement in HAP to levels still well above the WHO recommended limits. The findings of this study emphasise the importance of accurately documenting the reduction in HAP exposure with any intervention, as some interventions may not significantly improve air quality.

The Cooking and Pneumonia Study (CAPS) is a cluster RCT of an advanced cookstove intervention to prevent pneumonia in children $<5$ years old in rural Malawi $[93,94]$. The advanced cookstove reduces emissions by as much as $90 \%$ by incorporating a fan that improves combustion efficiency. The trial

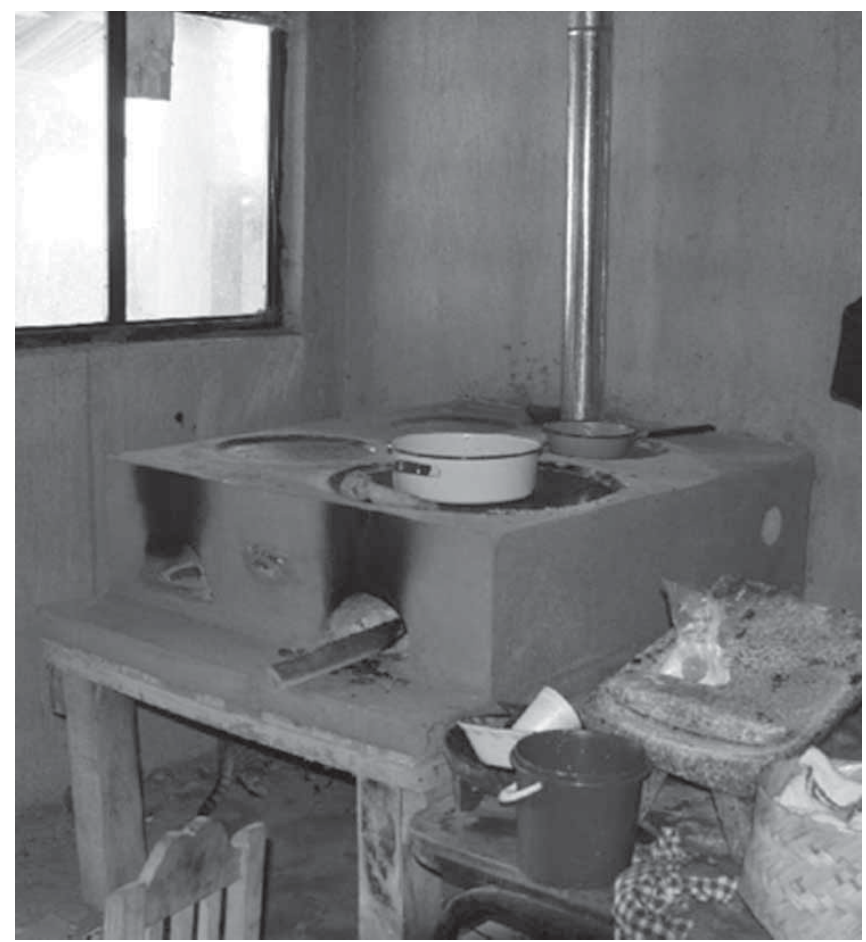

FIGURE 3 A Patsari wood-burning stove. The stove has a closed combustion chamber surrounded by bricks. A flat pottery dish or metal hotplate (called a comal and used for cooking tortillas) is integrally built into the surface of the stove, which has a smaller entrance for feeding fuel and a flue that passes through the roof and conveys the smoke outdoors. Reproduced from [92] with permission. 

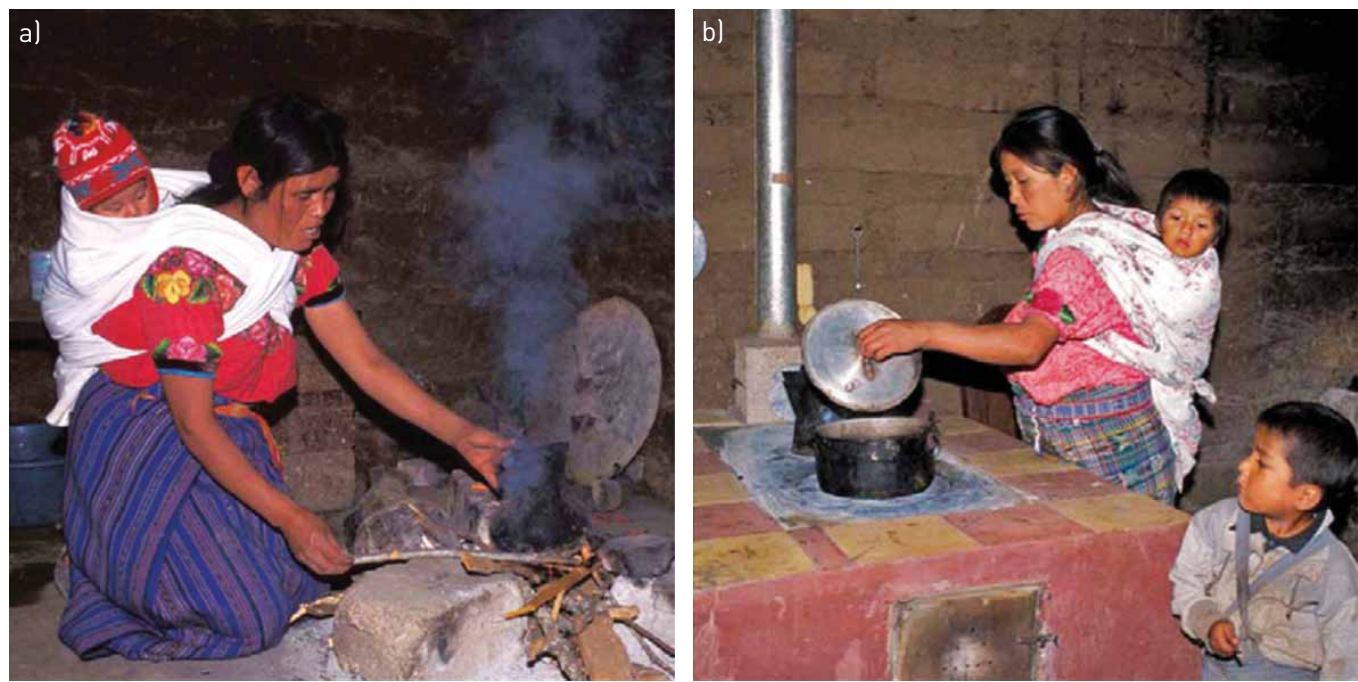

FIGURE 4 a) Traditional open fire used for cooking, and b) the locally developed and constructed chimney woodstove, the plancha, in Guatemala. The chimney woodstove has a thick metal heating surface for cooking tortillas and holes with removable concentric rings for pots, a firebrick combustion chamber with baffling, a concrete and brick body, tile surfaces around the cooking area, dirt and pumice stone insulation, a metal fuel door, and a metal chimney with a damper. Infants and toddlers are highly exposed to combustion smoke as they are carried on their mother's back while she cooks, a common cultural practice in Guatemala and other regions. Reproduced from [91] with permission.

recruited 10750 children from 8626 households across 150 village-level clusters randomised to receive the intervention (two Philips fan-assisted stoves with a solar charger per household) or continuation of traditional cooking methods. The primary outcome was the incidence of pneumonia in children under the age of 5 years, diagnosed by healthcare providers blinded to trial arm, using the WHO Integrated Management of Childhood Illness pneumonia assessment protocol, over 2 years of follow-up [94]. In this study, the intervention did not reduce the risk of pneumonia in young children. Exposure data have yet to be published from CAPS, but are necessary for a more comprehensive interpretation of the negative results of the trial. An important implication of these results is that addressing any individual source of air pollution exposure in isolation may not be effective for improving health; an integrated approach to achieving clean air that deals with rubbish disposal, tobacco smoking and other exposures, as well as robust cleaner cooking solutions (e.g. cleaner stoves and fuels) that achieve a high rate of acceptance may be more effective in delivering health benefits.

Additional trials have been underway in Africa and Nepal that are expected to report soon [95, 96]. The Ghana Randomised Air Pollution and Health Study (GRAPHS) is a three-arm (control, BioLite or an efficient biomass cookstove and liquefied petroleum gas) cluster randomised trial among 1415 maternal infant pairs in rural Ghana evaluating effects on birthweight and pneumonia in the first year of life [96]. More evidence is needed from well-conducted large-scale clinical trials about the health impacts of interventions to decrease HAP. There is currently a greater emphasis on the roll-out of cookstoves compared with evidence generation. This may turn out to be a mistake if non-evidence-based interventions are rolled out on scale and subsequently turn out to have little health benefits, particularly in light of the negative CAPS trial [94]. There needs to be more emphasis on the evaluation of the impact of interventions on health outcomes compared with air pollution, which (from a health perspective) is only an intermediate outcome. There are opportunities to think big and leap ahead with new technologies. The addictive biomass (i.e. tobacco) epidemic is a major threat and needs to be addressed in a way that is integrated with HAP reduction strategies if all the benefits of the latter are not to be undone by the former.

A major US National Institutes of Health (NIH)-funded multicentre RCT was recently initiated with sites in Rwanda, Peru, Guatemala and India. Instead of using improved biomass stoves, all sites in this set of RCTs are deploying LPG fuel as the study intervention. Results of this and other studies may further our understanding of the appropriate "best" intervention with respect to health outcomes.

\section{Useful interventions in high-income countries}

Wood burning is an important source of HAP in high-income countries, particularly in rural communities. Intervention strategies for reducing the health burden from HAP exposure in high-income countries include community-level and household-level approaches. 
One promising community-level strategy is fuel switching, typified by aggressive policies and incentives to promote a shift in heating fuels from biomass to cleaner energy sources such as natural gas and electricity. For example, the community of Launceston in Tasmania, Australia engaged in a large-scale effort to replace wood heating appliances with electric heating appliances, resulting in a $38 \%$ reduction in outdoor winter PM10 (i.e. particulate matter with median aerodynamic diameter $\leqslant 10 \mu \mathrm{m}$ ) and corresponding mortality reduction [97]. A second popular strategy to address elevated particulate matter concentrations in communities with a high frequency of wood burning is to replace conventional wood stoves with improved technology stoves. For example, a community-wide wood stove change-out programme in a small mountain community in the USA substantially reduced winter ambient levels of PM2.5 and PAHs, with corresponding reductions in frequency of children's respiratory symptoms and conditions [98, 99]. Despite apparent improvements in ambient air quality following wood stove technology upgrades, improvements to HAP have been less evident [100-103]. These community-level strategies (i.e. fuel switching and stove technology upgrades) are often legislative- or regulatory-driven. Municipal policy and enforcement efforts in the absence of targeted funding for fuel switching or stove technology upgrades may be slow in affecting change [104].

Plug-in air filter devices are efficacious household-level strategy for improving indoor air quality in homes using wood stoves $[103,105]$. For example, a recent randomised trial testing the efficacy of an air filter intervention in wood stove homes showed an overall 63\% (95\% CI 47-75\%) reduction in indoor PM2.5 for air filter homes relative to placebo control homes [103]. These filtration systems do not, however, remove nonparticulate matter gaseous pollutants such as ozone and nitrogen oxides. As a stand-alone strategy, the impact of air filters does not extend to the ambient environment, and compliance issues due to concerns of noise and operating cost may impact effectiveness. Finally, the promotion of best-burn practices such as proper combustion techniques and the use of dry wood fuels is a promising, but untested, approach that could be employed in communities that are unlikely to switch away from wood as a heating fuel source.

\section{Need for research support}

There is a great need for federal governmental research agencies such as the NIH in the USA to fund additional research in this area. There are also myriad private organisations and philanthropists that support biomedical research around the world, each with their own research agenda and tradition of funding. The strategic challenge ahead is how to prioritise which organisations are most likely to advance the importance of HAP as a future area of research that could effectively reduce the burden of disease. In order to achieve that goal, we must continue to increase awareness of HAP and important advances in relevant research. The scientific respiratory community must communicate more effectively with research organisations and their supporters that HAP is a major preventable cause of death in the world today and that almost half the deaths are attributable to respiratory diseases [5]. The recent growth in scientific evidence about HAP strongly supports the importance of this issue and the potential to develop scalable solutions that can reduce exposures and improve the lives of millions of people.

As noted in the Introduction, the Global Alliance for Clean Cookstoves initiative hosted by the United Nations Foundation to enable the distribution of 100 million clean stoves by 2020 and the initiatives of the governments of a number of countries, including Ghana, Senegal, Indonesia, Brazil and India, to accelerate the progression away from biomass to clean fuels provide a major impetus to conduct research needed to address data gaps in this field. The largest of these programmes currently is in India, which targets to connect 100 million biomass-using households to LPG within 10 years or so.

In the past, awareness of the health effects from HAP was insufficient by itself to improve organisational funding priorities to support HAP. The common refrain from funders was that there was no proof that a cleaner cooking solution could reduce HAP-related deaths. This of course started changing with the report of the RESPIRE study in 2011 [91]. A recent Lancet Editorial acknowledged that HAP "has not previously received as much attention as it deserves" [106]. The Editorial did note that the publication of three reports in 2014 (the WHO Indoor Air Quality guidelines [107], the Institute for Health Metrics and Evaluation report on indoor pollution and deaths [108], and The Lancet Respiratory Medicine Commission on HAP [59]) "has done much to change that". There is reason for optimism.

The future financial support to reduce the global burden of disease from HAP is predicated on increasing awareness among the scientific community, policy makers and the public. There already are effective partnerships around the world addressing this problem, but much more private research support is needed to leverage the largely publically funded efforts. However, there are many competing and important agendas in global health trying to gain attention from research funders. But perhaps Maria Neira of the WHO said it best when commenting on the importance of prevention of childhood pneumonia, "The best vaccine for pneumonia is ensuring that kids don't breathe dirty air at home" [109]. There is a need to communicate this message to research funders more clearly and effectively. And as this Lancet Editorial 
concludes, "This is real public health - primary prevention", notes Neira. "And it could be the public health legacy of the 21st century" [109].

\section{References}

1 World Health Organization. Household air pollution and health. Fact sheet 292. www.WHO.int/mediacentre/ factsheets/fs292/en/ Date last accessed: February 15, 2017. Date last updated: February 2016.

2 Sood A. Indoor fuel exposure and the lung in both developing and developed countries: an update. Clin Chest Med 2012; 33: 649-665.

3 Kim KH, Jahan SA, Kabir E. A review of diseases associated with household air pollution due to the use of biomass fuels. J Hazard Mater 2011; 192: 425-431.

$4 \quad$ Perez-Padilla R, Schilmann A, Riojas-Rodriguez H. Respiratory health effects of indoor air pollution. Int J Tuberc Lung Dis 2010; 14: 1079-1086.

5 Lim SS, Vos T, Flaxman AD, et al. A comparative risk assessment of burden of disease and injury attributable to 67 risk factors and risk factor clusters in 21 regions, 1990-2010: a systematic analysis for the Global Burden of Disease Study 2010. Lancet 2012; 380: 2224-2260.

6 Bonjour S, Adair-Rohani H, Wolf J, et al. Solid fuel use for household cooking: country and regional estimates for 1980-2010. Environ Health Perspect 2013; 121: 784-790.

$7 \quad$ Kraai S, Verhagen LM, Valladares E, et al. High prevalence of asthma symptoms in Warao Amerindian children in Venezuela is significantly associated with open-fire cooking: a cross-sectional observational study. Respir Res 2013; 14: 76.

8 Oluwole O, Arinola GO, Huo D, et al. Biomass fuel exposure and asthma symptoms among rural school children in Nigeria. J Asthma 2017; 54: 347-356.

9 Gaviola $\mathrm{C}$, Miele $\mathrm{CH}$, Wise RA, et al. Urbanisation but not biomass fuel smoke exposure is associated with asthma prevalence in four resource-limited settings. Thorax 2016; 71: 154-160.

10 Lin HH, Suk CW, Lo HL, et al. Indoor air pollution from solid fuel and tuberculosis: a systematic review and meta-analysis. Int J Tuberc Lung Dis 2014; 18: 613-621.

11 Smith KR, Bruce N, Balakrishnan K, et al. Millions dead: how do we know and what does it mean? Methods used in the comparative risk assessment of household air pollution. Annu Rev Public Health 2014; 35: 185-206.

12 Naeher LP, Brauer M, Lipsett M, et al. Woodsmoke health effects: a review. Inhal Toxicol 2007; 19: 67-106.

13 Smith KR. Biofuels, Air Pollution, and Health. 1st Edn. New York, Plenum Press, 1987.

14 Ng M, Freeman MK, Fleming TD, et al. Smoking prevalence and cigarette consumption in 187 countries, 1980 2012. JAMA 2014; 311: 183-192.

15 Burnett RT, Pope CA 3rd, Ezzati M, et al. An integrated risk function for estimating the global burden of disease attributable to ambient fine particulate matter exposure. Environ Health Perspect 2014; 122: 397-403.

16 Pope CA 3rd, Burnett RT, Thun MJ, et al. Lung cancer, cardiopulmonary mortality, and long-term exposure to fine particulate air pollution. JAMA 2002; 287: 1132-1141.

17 Pope CA 3rd, Burnett RT, Turner MC, et al. Lung cancer and cardiovascular disease mortality associated with ambient air pollution and cigarette smoke: shape of the exposure-response relationships. Environ Health Perspect 2011; 119: 1616-1621.

18 Smith KR, Peel JL. Mind the gap. Environ Health Perspect 2010; 118: 1643-1645.

19 Martin WJ 2nd, Glass RI, Araj H, et al. Household air pollution in low- and middle-income countries: health risks and research priorities. PLoS Med 2013; 10: e1001455.

20 Postma DS, Bush A, van den Berge M. Risk factors and early origins of chronic obstructive pulmonary disease. Lancet 2015; 385: 899-909.

21 Rylance J, Gordon SB, Naeher LP, et al. Household air pollution: a call for studies into biomarkers of exposure and predictors of respiratory disease. Am J Physiol Lung Cell Mol Physiol 2013; 304: L571-L578.

22 World Health Organization. D7: Evaluating household energy and health interventions: a catalogue of methods. 2012. www.who.int/indoorair/publications/methods/d7/en/index.html Date last accessed: February 15, 2017.

23 Irshad HM, Meek PM, Petersen H, et al. Association between self-report questions and measurements of indoor wood smoke concentrations. Am J Respir Crit Care Med 2015; 191: A4038.

24 Loo CK, Foty RG, Wheeler AJ, et al. Do questions reflecting indoor air pollutant exposure from a questionnaire predict direct measure of exposure in owner-occupied houses? Int J Environ Res Public Health 2010; 7: 3270-3297.

25 Mahesh PA, Jayaraj BS, Prabhakar AK, et al. Identification of a threshold for biomass exposure index for chronic bronchitis in rural women of Mysore district, Karnataka, India. Indian J Med Res 2013; 137: 87-94.

26 Smith KR, McCracken JP, Thompson L, et al. Personal child and mother carbon monoxide exposures and kitchen levels: methods and results from a randomized trial of woodfired chimney cookstoves in Guatemala (RESPIRE). J Expo Sci Environ Epidemiol 2010; 20: 406-416.

27 Carter E, Norris C, Dionisio KL, et al. Assessing exposure to household air pollution: a systematic review and pooled analysis of carbon monoxide as a surrogate measure of particulate matter. Environ Health Perspect 2017; 125: 076002.

28 Torres-Dosal A, Perez-Maldonado IN, Jasso-Pineda Y, et al. Indoor air pollution in a Mexican indigenous community: evaluation of risk reduction program using biomarkers of exposure and effect. Sci Total Environ 2008; 390: 362-368.

29 Eppler AR, Fitzgerald C, Dorner SC, et al. Using exhaled carbon monoxide and carboxyhemoglobin to evaluate the effectiveness of a chimney stove model in Peru. Int J Occup Environ Health 2013; 19: 325-331.

30 Pope D, Diaz E, Smith-Sivertsen T, et al. Exposure to household air pollution from wood combustion and association with respiratory symptoms and lung function in nonsmoking women: results from the RESPIRE trial, Guatemala. Environ Health Perspect 2015; 123: 285-292.

31 Maisel WH, Lewis RJ. Noninvasive measurement of carboxyhemoglobin: how accurate is accurate enough? Ann Emerg Med 2010; 56: 389-391.

32 Dills RL, Paulsen M, Ahmad J, et al. Evaluation of urinary methoxyphenols as biomarkers of woodsmoke exposure. Environ Sci Technol 2006; 40: 2163-2170. 

comparisons in rural Guatemala with personal $\mathrm{CO}$ and kitchen $\mathrm{CO}$, levoglucosan, and $\mathrm{PM}_{2.5}$. Environ Sci Technol 2007; 41: 3481-3487.

34 Neitzel R, Naeher LP, Paulsen M, et al. Biological monitoring of smoke exposure among wildland firefighters: a pilot study comparing urinary methoxyphenols with personal exposures to carbon monoxide, particular matter, and levoglucosan. J Expo Sci Environ Epidemiol 2009; 19: 349-358.

35 Migliaccio CT, Bergauff MA, Palmer CP, et al. Urinary levoglucosan as a biomarker of wood smoke exposure observations in a mouse model and in children. Environ Health Perspect 2009; 117: 74-79.

36 Bergauff MA, Ward TJ, Noonan CW, et al. Urinary levoglucosan as a biomarker of wood smoke: results of human exposure studies. J Expo Sci Environ Epidemiol 2010; 20: 385-392.

37 Adetona $\mathrm{O}$, Sjodin $\mathrm{A}$, Zheng $\mathrm{L}$, et al. Personal exposure to $\mathrm{PM}_{2.5}$ and urinary hydroxy-PAH levels in bus drivers exposed to traffic exhaust, in Trujillo, Peru. J Occup Environ Hyg 2012; 9: 217-229.

38 Riojas-Rodriguez H, Schilmann A, Marron-Mares AT, et al. Impact of the improved Patsari biomass stove on urinary polycyclic aromatic hydrocarbon biomarkers and carbon monoxide exposures in rural Mexican women. Environ Health Perspect 2011; 119: 1301-1307.

39 Shapiro D, Deering-Rice CE, Romero EG, et al. Activation of transient receptor potential ankyrin-1 (TRPA1) in lung cells by wood smoke particulate material. Chem Res Toxicol 2013; 26: 750-758.

40 Danielsen PH, Loft S, Kocbach A, et al. Oxidative damage to DNA and repair induced by Norwegian wood smoke particles in human A549 and THP-1 cell lines. Mutat Res 2009; 674: 116-122.

41 Danielsen PH, Moller P, Jensen KA, et al. Oxidative stress, DNA damage, and inflammation induced by ambient air and wood smoke particulate matter in human A549 and THP-1 cell lines. Chem Res Toxicol 2011; 24: $168-184$.

42 Saikia BJ, Das M, Sharma SK, et al. Association of a p53 codon 72 gene polymorphism with environmental factors and risk of lung cancer: a case control study in Mizoram and Manipur, a high incidence region in North East India. Asian Pac J Cancer Prev 2014; 15: 10653-10658.

43 Delgado J, Martinez LM, Sanchez TT, et al. Lung cancer pathogenesis associated with wood smoke exposure. Chest 2005; 128: 124-131.

44 Kocbach A, Namork E, Schwarze PE. Pro-inflammatory potential of wood smoke and traffic-derived particles in a monocytic cell line. Toxicology 2008; 247: 123-132.

45 Lee TS, Liu YJ, Tang GJ, et al. Wood smoke extract promotes both apoptosis and proliferation in rat alveolar epithelial type II cells: the role of oxidative stress and heme oxygenase-1. Crit Care Med 2008; 36: 2597-2606.

46 Liu PL, Chen YL, Chen YH, et al. Wood smoke extract induces oxidative stress-mediated caspase-independent apoptosis in human lung endothelial cells: role of AIF and EndoG. Am J Physiol Lung Cell Mol Physiol 2005; 289: L739-L749.

47 Ramos C, Cisneros J, Gonzalez-Avila G, et al. Increase of matrix metalloproteinases in woodsmoke-induced lung emphysema in guinea pigs. Inhal Toxicol 2009; 21: 119-132

48 Tesfaigzi Y, McDonald JD, Reed MD, et al. Low-level subchronic exposure to wood smoke exacerbates inflammatory responses in allergic rats. Toxicol Sci 2005; 88: 505-513.

49 Awji EG, Chand H, Bruse S, et al. Wood smoke enhances cigarette smoke-induced inflammation by inducing the aryl hydrocarbon receptor repressor in airway epithelial cells. Am J Respir Cell Mol Biol 2015; 52: 377-386.

50 Holian A, Scheule RK. Alveolar macrophage biology. Hosp Pract (Off Ed) 1990; 25: 53-62.

51 Fullerton DG, Suseno A, Semple S, et al. Wood smoke exposure, poverty and impaired lung function in Malawian adults. Int J Tuberc Lung Dis 2011; 15: 391-398.

52 Kulkarni NS, Prudon B, Panditi SL, et al. Carbon loading of alveolar macrophages in adults and children exposed to biomass smoke particles. Sci Total Environ 2005; 345: 23-30.

53 van Eeden SF, Tan WC, Suwa T, et al. Cytokines involved in the systemic inflammatory response induced by exposure to particulate matter air pollutants $\left(\mathrm{PM}_{10}\right)$. Am J Respir Crit Care Med 2001; 164: 826-830.

54 Tellabati A, Fernandes VE, Teichert F, et al. Acute exposure of mice to high-dose ultrafine carbon black decreases susceptibility to pneumococcal pneumonia. Part Fibre Toxicol 2010; 7: 30.

55 Kulkarni N, Pierse N, Rushton L, et al. Carbon in airway macrophages and lung function in children. $N$ Engl $J$ Med 2006; 355: 21-30.

56 Rylance J, Fullerton DG, Scriven J, et al. Household air pollution causes dose-dependent inflammation and altered phagocytosis in human macrophages. Am J Respir Cell Mol Biol 2015; 52: 584-593.

57 Rylance J, Chimpini C, Semple S, et al. Chronic household air pollution exposure is associated with impaired alveolar macrophage function in Malawian non-smokers. PLoS One 2015; 10: e0138762.

58 Ferkol T, Schraufnagel D. The global burden of respiratory disease. Ann Am Thorac Soc 2014; 11: 404-406.

59 Gordon SB, Bruce NG, Grigg J, et al. Respiratory risks from household air pollution in low and middle income countries. Lancet Respir Med 2014;2:823-860.

60 Sleeman KL, Daniels L, Gardiner M, et al. Acquisition of Streptococcus pneumoniae and nonspecific morbidity in infants and their families: a cohort study. Pediatr Infect Dis J 2005; 24: 121-127.

61 Rylance J, Kankwatira A, Nelson DE, et al. Household air pollution and the lung microbiome of healthy adults in Malawi: a cross-sectional study. BMC Microbiol 2016; 16: 182.

62 Roy A, Chapman RS, Hu W, et al. Indoor air pollution and lung function growth among children in four Chinese cities. Indoor Air 2012; 22: 3-11.

63 Rojas-Martinez R, Perez-Padilla R, Olaiz-Fernandez G, et al. Lung function growth in children with long-term exposure to air pollutants in Mexico City. Am J Respir Crit Care Med 2007; 176: 377-384.

64 Horak F Jr, Studnicka M, Gartner C, et al. Particulate matter and lung function growth in children: a 3-yr follow-up study in Austrian schoolchildren. Eur Respir J 2002; 19: 838-845.

65 Gauderman WJ, Gilliland GF, Vora H, et al. Association between air pollution and lung function growth in southern California children: results from a second cohort. Am J Respir Crit Care Med 2002; 166: 76-84.

66 Gauderman WJ, Avol E, Gilliland F, et al. The effect of air pollution on lung development from 10 to 18 years of age. N Engl J Med 2004; 351: 1057-1067.

67 Shen S, Qin Y, Cao Z, et al. Indoor air pollution and pulmonary function in children. Biomed Environ Sci 1992; 5: $136-141$ 
Zhang JJ, Smith KR. Household air pollution from coal and biomass fuels in China: measurements, health impacts, and interventions. Environ Health Perspect 2007; 115: 848-855.

Devakumar D, Stocks J, Ayres JG, et al. Effects of antenatal multiple micronutrient supplementation on lung function in mid-childhood: follow-up of a double-blind randomised controlled trial in Nepal. Eur Respir J 2015; 45: $1566-1575$.

Orozco-Levi M, Garcia-Aymerich J, Villar J, et al. Wood smoke exposure and risk of chronic obstructive pulmonary disease. Eur Respir J 2006; 27: 542-546.

A, Petersen H, Blanchette CM, et al. Wood smoke exposure and gene promoter methylation are associated with increased risk for COPD in smokers. Am J Respir Crit Care Med 2010; 182: 1098-1104.

Tan WC, Sin DD, Bourbeau J, et al. Characteristics of COPD in never-smokers and ever-smokers in the general population: results from the CanCOLD study. Thorax 2015; 70: 822-829.

Salvi SS, Barnes PJ. Chronic obstructive pulmonary disease in non-smokers. Lancet 2009; 374: 733-743.

Salvi S, Barnes PJ. Is exposure to biomass smoke the biggest risk factor for COPD globally? Chest 2010; 138: 3-6. Ramirez-Venegas A, Sansores RH, Perez-Padilla R, et al. Survival of patients with chronic obstructive pulmonary disease due to biomass smoke and tobacco. Am J Respir Crit Care Med 2006; 173: 393-397.

Ramirez-Venegas A, Sansores RH, Quintana-Carrillo RH, et al. Forced expiratory volume in one second decline in patients with chronic obstructive pulmonary disease associated with biomass exposure. Am J Respir Crit Care Med 2014; 190: 996-1002.

Camp PG, Ramirez-Venegas A, Sansores RH, et al. COPD phenotypes in biomass smoke- versus tobacco smoke-exposed Mexican women. Eur Respir J 2014; 43: 725-734.

Gonzalez-Garcia M, Maldonado Gomez D, Torres-Duque CA, et al. Tomographic and functional findings in severe COPD: comparison between the wood smoke-related and smoking-related disease. J Bras Pneumol 2013; 39: 147-154.

Gonzalez-Garcia M, Torres-Duque CA, Bustos A, et al. Bronchial hyperresponsiveness in women with chronic obstructive pulmonary disease related to wood smoke. Int J Chron Obstruct Pulmon Dis 2012; 7: 367-373.

Torres-Duque C, Maldonado D, Perez-Padilla R, et al. Biomass fuels and respiratory diseases: a review of the evidence. Proc Am Thorac Soc 2008; 5: 577-590.

Golpe R, Sanjuan Lopez P, Cano Jimenez E, et al. Distribution of clinical phenotypes in patients with chronic obstructive pulmonary disease caused by biomass and tobacco smoke. Arch Bronconeumol 2014; 50: 318-324.

Dutta A, Ray MR, Banerjee A. Systemic inflammatory changes and increased oxidative stress in rural Indian women cooking with biomass fuels. Toxicol Appl Pharmacol 2012; 261: 255-262.

Turner MC, Chen Y, Krewski D, et al. Chronic obstructive pulmonary disease is associated with lung cancer mortality in a prospective study of never smokers. Am J Respir Crit Care Med 2007; 176: 285-290.

Taylor AE, Finney-Hayward TK, Quint JK, et al. Defective macrophage phagocytosis of bacteria in COPD. Eur Respir J 2010; 35: 1039-1047.

Lange P, Celli B, Agusti A. Lung-function trajectories and chronic obstructive pulmonary disease. N Engl J Med 2015; 373: 1575.

Rivera RM, Cosio MG, Ghezzo H, et al. Comparison of lung morphology in COPD secondary to cigarette and biomass smoke. Int J Tuberc Lung Dis 2008; 12: 972-977.

Mukhopadhyay S, Gujral M, Abraham JL, et al. A case of hut lung: scanning electron microscopy with energy dispersive $\mathrm{x}$-ray spectroscopy analysis of a domestically acquired form of pneumoconiosis. Chest 2013; 144: 323-327.

Ramage JE Jr, Roggli VL, Bell DY, et al. Interstitial lung disease and domestic wood burning. Am Rev Respir Dis 1988; 137: 1229-1232.

Churg A, Wright JL, Wiggs B, et al. Small airways disease and mineral dust exposure. Prevalence, structure, and function. Am Rev Respir Dis 1985; 131: 139-143.

Romieu I, Riojas-Rodriguez H, Marron-Mares AT, et al. Improved biomass stove intervention in rural Mexico: impact on the respiratory health of women. Am J Respir Crit Care Med 2009; 180: 649-656.

Smith KR, McCracken JP, Weber MW, et al. Effect of reduction in household air pollution on childhood pneumonia in Guatemala (RESPIRE): a randomised controlled trial. Lancet 2011; 378: 1717-1726.

Zuk M, Rojas L, Blanco S, et al. The impact of improved wood-burning stoves on fine particulate matter concentrations in rural Mexican homes. J Expo Sci Environ Epidemiol 2007; 17: 224-232.

Kalu N, Lufesi N, Havens D, et al. Implementation of World Health Organization Integrated Management of Childhood Illnesses (IMCI) guidelines for the assessment of pneumonia in the under $5 \mathrm{~s}$ in rural Malawi. PLoS One 2016; 11: e0155830.

Mortimer K, Ndamala CB, Naunje AW, et al. A cleaner burning biomass-fuelled cookstove intervention to prevent pneumonia in children under 5 years old in rural Malawi (the Cooking and Pneumonia Study): a cluster randomised controlled trial. Lancet 2017; 389: 167-175.

Tielsch JM, Katz J, Zeger SL, et al. Designs of two randomized, community-based trials to assess the impact of alternative cookstove installation on respiratory illness among young children and reproductive outcomes in rural Nepal. BMC Public Health 2014; 14: 1271.

Jack DW, Asante KP, Wylie BJ, et al. Ghana randomized air pollution and health study (GRAPHS): study protocol for a randomized controlled trial. Trials 2015; 16: 420.

Johnston FH, Hannigan IC, Henderson SB, et al. Evaluation of interventions to reduce air pollution from biomass smoke on mortality in Launceston, Australia: retrospective analysis of daily mortality, 1994-2007. Br Med J 2013; 346: e8446.

98 Noonan CW, Ward TJ, Navidi W, et al. A rural community intervention targeting biomass combustion sources: effects on air quality and reporting of children's respiratory outcomes. Occup Environ Med 2012; 69: 354-360.

Ward TJ, Palmer CP, Houck JE, et al. Community woodstove changeout and impact on ambient concentrations of polycyclic aromatic hydrocarbons and phenolics. Environ Sci Technol 2009; 43: 5345-5350.

Noonan CW, Navidi W, Sheppard L, et al. Residential indoor $\mathrm{PM}_{2.5}$ in wood stove homes: follow-up of the Libby changeout program. Indoor Air 2012; 22: 492-500.

en R, Leckie S, Millar G, et al. The impact of wood stove technology upgrades on indoor residential air quality. Atmospheric Environment 2009; 43: 5908-5915. 
102 Ward T, Boulafentis J, Simpson J, et al. Lessons learned from a woodstove changeout on the Nez Perce Reservation. Sci Total Environ 2011; 409: 664-670

103 Ward TJ, Semmens EO, Weiler E, et al. Efficacy of interventions targeting household air pollution from residential wood stoves. J Expo Sci Environ Epidemiol 2017; 27: 64-71.

104 Missoula City County Health Department. A History of Missoula's Air Quality Program. 2016. www. missoulacounty.us/home/showdocument?id=18812 Date last accessed: February 15, 2017. Last updated: July 2016.

105 Allen RW, Carlsten C, Karlen B, et al. An air filter intervention study of endothelial function among healthy adults in a woodsmoke-impacted community. Am J Respir Crit Care Med 2011; 183: 1222-1230.

106 Editorial. Improving air quality starts at home. Lancet 2014; 384: 1821.

107 World Health Organization. WHO sets benchmarks to reduce health damage from indoor air pollution. 2014. www.who.int/mediacentre/news/releases/2014/indoor-air-pollution/en/ Date last accessed: September 30, 2015.

108 Institute for Health Metrics and Evaluation. Pushing the Pace: Progress and Challenges in Fighting Childhood Pneumonia. 2014. www.healthdata.org/sites/default/files/files/policy_report/2014/PolicyReport IHME_PushingthePace_2014.pdf Date last accessed: February 15, 2017.

109 Burki TK. Burning issues: tackling indoor air pollution. Lancet 2011; 377: 1559-1560. 